\title{
Thyroid Carcinoma in Hot Nodules: Review of the Literature
}

Pouya Iranmanesh, Marc Pusztaszeri, John Robert, Patrick Meyer, Boris Schiltz, Samira Mercedes Sadowski

Michel Olivier Goumaz, Frederic Triponez

\begin{abstract}
Thyroid hot nodules are virtually always considered benign. Rare cases of hot thyroid carcinoma exist. We briefly described a clinical case and performed a review of the literature. We performed an extensive research on medical databases, such as PubMed and compiled all published cases matching preset criteria defining true hot thyroid carcinomas as well as guidelines regarding their management. We analyzed 103 articles published over the past 50 years. We selected 16 articles, including 45 cases matching our criteria. The majority were follicular carcinomas. Papillary carcinomas were infrequently found in this setting. Recommended management and survival rates were similar to classical cold thyroid cancer. Although hot nodules should continue to be considered benign most of the time, rare cases of hot thyroid cancers exist and clinicians should not hesitate to ask for additional tests if they encounter any abnormal finding. This form of thyroid cancer can reasonably be managed the same way as the cold thyroid cancers.
\end{abstract}

Keywords: Thyroid cancer, Thyroid carcinoma, Thyroid surgery, Hot thyroid nodule.

How to cite this article: Iranmanesh $\mathrm{P}$, Pusztaszeri $\mathrm{M}$, Robert J, Meyer P, Schiltz B, Sadowski SM, Goumaz MO, Triponez F. Thyroid Carcinoma in Hot Nodules: Review of the Literature. World J Endoc Surg 2013;5(2):50-54.

\section{Source of support: Nil}

Conflict of interest: None

\section{INTRODUCTION}

Medical literature generally has admitted for several decades that concurrent thyroid cancer and hyperthyroidism is a rare association. ${ }^{1-3}$ The overall low incidence, however, makes it difficult to draw adequate statistics. The few larger retrospective series mention an incidence of thyroid cancer among hyperthyroid patients between 1 and 5.8\%. ${ }^{4-8}$ According to the latest guidelines from the American Thyroid Association, ${ }^{9}$ hyperthyroid nodules with positive radioactive marker uptake on scintigraphy do not require fine-needle aspiration (FNA) or ultrasound evaluation because of the overall low incidence of malignancy in these lesions. Moreover, a significant number of FNA performed in hot nodules are diagnosed as 'suspicious for a follicular neoplasm' (category IV in the Bethesda grading system), which would result in an increased number of thyroidectomies performed for benign disease. Hot nodules are therefore considered virtually benign and managed as such in most institutions, including ours. We recently had the case of a patient with a hypersecreting thyroid nodule which was found to be a papillary carcinoma. We here describe this clinical case and take it as an opportunity to analyze and review the literature concerning this topic.

\section{CASE REPORT}

A 54-year-old, nonsmoking female patient without any significant medical history was evaluated in November 2011 for a right thyroid nodule. She did not complain of any symptoms except moderate cervical discomfort. Her vital signs were all normal and her physical examination was unremarkable except for an enlarged, painless right thyroid lobe. There were no palpable cervical lymph nodes. Laboratory measurements showed very low serum thyroid stimulating hormone (TSH) levels $(0.013 \mathrm{mU} / \mathrm{l}$, normal levels 0.340-5.60) and upper limits free tetraiodothyronine (T4) (14 pmol/l, normal levels 7.9-14.4) and triiodothyronine (T3) (6.5 pmol/l, normal levels 3.8-6.8) serum levels. An ultrasound showed a solitary, $23 \times 17 \times 16 \mathrm{~mm}$, well-delimited, hyperechogenic nodule located at the inferior pole of the right thyroid lobe (Figs 1 and 2), without evidence of cervical lymph node enlargement. The ${ }^{99 \mathrm{~m}} \mathrm{TC}$ pertechnetate thyroid scintigraphy was positive for a single hyperfunctional nodule located at the inferior part of the right thyroid lobe as well. The nodule showed increased radioactive marker uptake, whereas the remaining thyroid showed a diminished marker uptake (Fig. 3). After detailed explanations about both surgical and radioactive-iodine treatment options and their respective benefits and risks, the patient chose the surgical option. We planned a classical right thyroid lobectomy and isthmectomy for her right solitary toxic nodule.

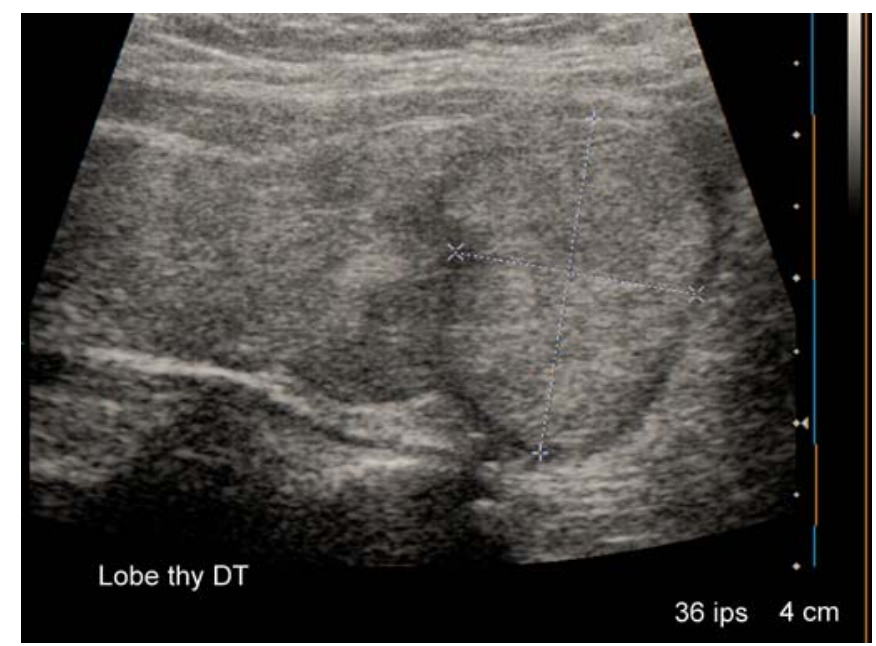

Fig. 1: Ultrasound image of the thyroid nodule-transverse view 
During the surgical procedure, the surgeon found a very firm nodule which showed clear signs of invasion into the overlying muscles and he decided to ask for a frozen section. The nodule was diagnosed as a thyroid papillary carcinoma. The thyroid lobectomy was therefore converted to a total thyroidectomy with central neck dissection. Both laryngeal recurrent nerves were monitored electrically and preserved. The postoperative period was uneventful and the patient was discharged 1 day after surgery.

The final histopathologic examination showed a follicular variant of papillary carcinoma of the right thyroid lobe with prethyroidal muscles infiltration (Figs 4A to D). The surrounding thyroid tissue and the left lobe exhibited a totally normal architecture, without any hyperplasia or other lesion. None of the lymph nodes contained metastatic disease. The tumor-node-metastasis (TNM) staging was pT3 pNO. The patient underwent a radioactive iodine treatment in April 2012.

\section{MATERIALS AND METHODS}

Usual online publication databases, mainly PubMed, were used to find and analyze all previously published cases of

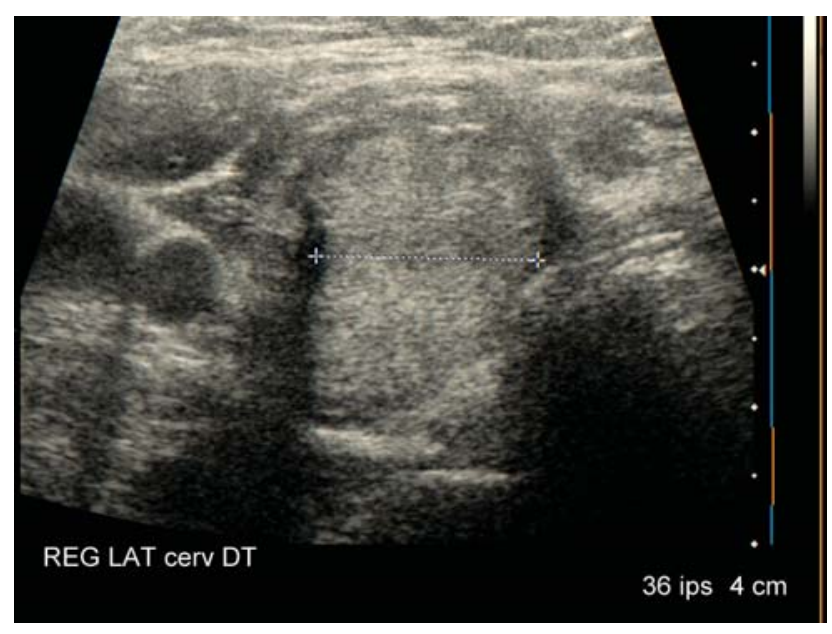

Fig. 2: Ultrasound image of the thyroid nodule-longitudinal view

Fig. 3: ${ }^{99 \mathrm{~m}} \mathrm{TC}$-pertechnetate thyroid scintigraphy showing the right hot nodule with suppressed surrounding thyroid tissue

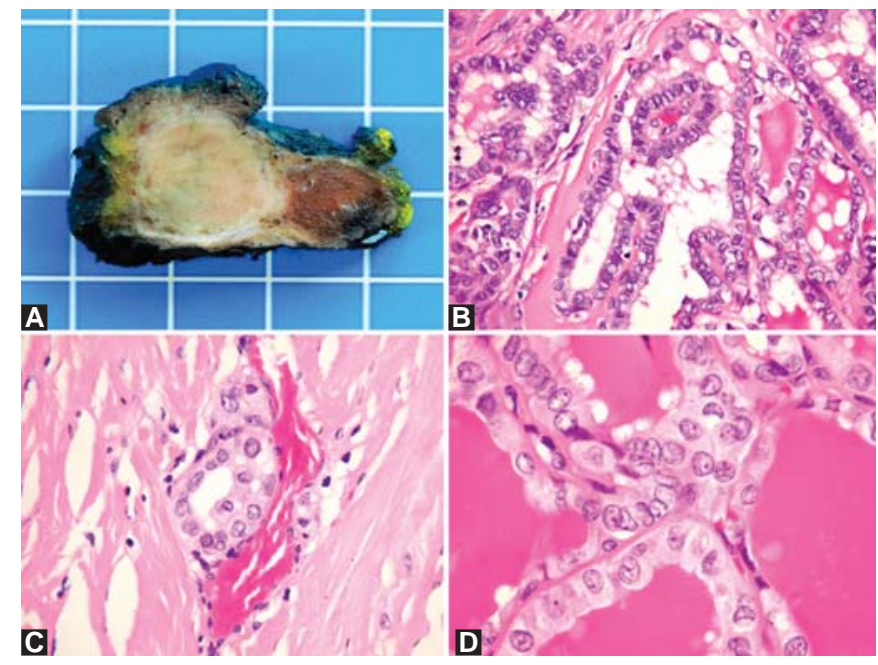

Figs 4A to D: (A) Macroscopic view of the right thyroid lobe showing a white nodule with irregular borders infiltrating perithyroid fat (1 square $=1 \mathrm{~cm}^{2}$ ), (B) microscopic view showing a follicular variant of papillary carcinoma with some abortive papillae (200xhematoxylin and eosin stain), (C) intravascular invasion by the carcinoma (200x-hematoxylin and eosin stain), (D) the nuclei show characteristic features of papillary carcinoma including ground-glass nuclei and nuclear grooves (400x-hematoxylin and eosin stain)

hot thyroid cancer. The following research terms were used, either individually or in combinations: thyroid, hyperthyroidism, hot, hypersecreting, hyperfunctional, nodule, cancer, neoplasia, tumor, carcinoma, papillary, follicular. All articles published before September 2012 were taken into consideration. According to previously published articles, ${ }^{10-13}$ we defined the following three criteria to define true cases of hypersecreting thyroid carcinoma: localized increased radioactive marker uptake on scintigraphy, decreased TSH levels and complete coincidence on histopathologic examination between the hypersecreting thyroid tissue and the thyroid carcinoma. Cases matching all three criteria were then compiled, including authors, date of publication, number of cases and histopathology of thyroid cancer.

Consensus papers and guidelines about hot thyroid cancers from recognized surgical and medical endocrine associations were searched and compiled as well.

\section{RESULTS}

A preliminary unfiltered search resulted in 103 articles related to hot thyroid carcinoma, published between October 1958 and September 2012.

All cases reporting thyroid cancer in hyperthyroid contexts like Grave's disease or Hashimoto thyroiditis were excluded as well as articles with insufficient information to evaluate our criteria and articles which did not describe clinical cases. This first filtering process selected 31 articles, describing a total of 69 reported cases of solitary toxic nodules associated with thyroid carcinoma. Out of these 
31 articles, 16 articles (five series of cases and 11 case reports) included cases matching the previously mentioned criteria for a total of 45 reported cases. ${ }^{6,7,11-24}$

Among these 45 cases, the histological repartition was as follow: 25 (56\%) follicular carcinoma, 16 (36\%) papillary carcinoma including at least four (9\%) confirmed follicular variant, two (4\%) Hürthle cells thyroid cancer, one (2\%) poorly differentiated thyroid cancer and we were not able to find the histology for one case (Table 1).

One article ${ }^{6}$ performed a survival analysis based on 19 cases and found similar matched 6-year survival rates compared to patients with cold thyroid cancer.

Two articles suggested a higher prevalence of cancer in hot nodules in children. ${ }^{13,25}$

Guidelines about the management of hot thyroid cancers were found in three articles, all of which were consensus articles from major surgical and medical associations.9,26,27

\section{DISCUSSION}

Our results confirm that hot thyroid carcinoma is a rare disease. The low number of cases and the absence of larger series explain the lack of solid data and well designed clinical trials. As mentioned before, the incidence appears to be somewhere between 1 and 6\% in patients with hyperthyroidism, with a probably higher figure among children.

The definition of hypersecreting thyroid carcinoma or hot thyroid cancer has been matter of debate for more than a decade. ${ }^{9}$ As mentioned by Lupi and al, ${ }^{10}$ it is important to distinguish between real cases of hot thyroid cancers and other situations like a coexisting thyroid carcinoma and toxic nodule, a carcinoma inside a toxic nodule or a carcinoma related to forms of hyperthyroidism that are not caused by hyperfunctional nodules. This is the rationale explaining the three criteria chosen to identify true cases of hot thyroid carcinoma respectively, the exclusion of the cases describing patients with Grave's disease or Hashimoto thyroiditis. The case we reported above fulfills all these criteria. As mentioned previously, 69 cases of solitary toxic nodules associated with thyroid carcinoma were found, among which 24 cases were excluded because they did not match the selected criteria, leaving the 45 cases presented in Table 1.

The larger series ${ }^{6,7}$ show a higher prevalence of follicular thyroid carcinomas, which represent more than half (56\%) of all cases we found. Since hot thyroid papillary carcinomas are found less frequently, they seem to be more often published as individual clinical cases: 11 out of 18 published case reports were papillary carcinomas. A significant fraction of these papillary carcinomas (minimum 25\%, probably more since the subtype of all papillary carcinomas could not be found), including those found in the larger series, are of the follicular variant. A possible explanation may be that the follicular variant produces more colloid than the conventional papillary carcinoma, in which colloid depletion is relatively common.

The guidelines set by major medical and surgical associations about the management of thyroid cancer are not very extensive about hot thyroid cancers and recognize the lack of data and properly designed studies in this field. No specific management for hot thyroid cancer is suggested. There is a general agreement that hot nodules should be considered benign and treated as such and, therefore, not undergo additional tests, such as FNA or ultrasound evaluation. Experts recommend the same management as classical thyroid carcinoma, primarily surgery followed by radioactive iodine therapy if needed (grade $\mathrm{C}$ recommendation).

In our opinion, clinicians should always look for abnormal and nonconcordant clinical and/or radiologic findings when faced with a hot thyroid nodule. Suspicious elements are similar to those encountered in classical forms of thyroid cancer and include symptoms, such as local pain, dyspnea, dysphonia or dysphagia, palpation of enlarged cervical lymph nodes, ultrasound findings, such as irregularly

\begin{tabular}{|c|c|c|c|}
\hline Authors & Year of publication & Number of cases & Histology of cancer \\
\hline Karanchi et al ${ }^{14}$ & 2012 & 1 & Hurthle cell \\
\hline Damle et $\mathrm{al}^{13}$ & 2011 & 2 & Papillary (subtype not found) \\
\hline Yalla et $\mathrm{al}^{15}$ & 2011 & 1 & Hurthle cell \\
\hline Giovanella et $\mathrm{al}^{16}$ & 2010 & 1 & Follicular \\
\hline Bommireddipalli et $\mathrm{al}^{17}$ & 2010 & 1 & Papillary, follicular variant \\
\hline Azevedo et $\mathrm{al}^{18}$ & 2010 & 1 & Papillary, follicular variant \\
\hline Uludag et $\mathrm{al}^{19}$ & 2008 & 1 & Papillary, columnary type \\
\hline Nishida et $\mathrm{al}^{12}$ & 2008 & 1 & Papillary (subtype not found) \\
\hline Low et $\mathrm{al}^{20}$ & 2005 & 1 & Poorly differentiated \\
\hline Als et $\mathrm{al}^{6}$ & 2002 & $1 \overline{7}$ & 14 follicular, 3 papillary including 2 follicular variant \\
\hline Lupi et $\mathrm{al}^{11}$ & 2002 & 1 & Not found \\
\hline Cirillo et $\mathrm{al}^{21}$ & 1998 & 1 & Papillary \\
\hline Ikekubo et al ${ }^{22}$ & 1989 & 3 & Papillary (subtype not found) \\
\hline Smith et $\mathrm{al}^{23}$ & 1988 & 2 & Follicular \\
\hline Sandler et $\mathrm{al}^{24}$ & 1988 & 1 & Papillary (subtype not found) \\
\hline Rösler et $\mathrm{al}^{7}$ & 1984 & 10 & 8 follicular, 2 papillary (subtype not found) \\
\hline
\end{tabular}


shaped tumor or invasion of surrounding structures. These findings should lead to additional tests, such as FNA or further radiologic studies. Sometimes, as was the case with the patient we described in this article, abnormal elements are found only during the operation. In this case, the surgeon should not hesitate to ask for a frozen section.

According to a survival analysis of 19 patients, the 5-year survival rate of patients with hot thyroid cancer treated by surgical resection followed by radioactive iodine is not significantly different after matching when compared to patients with classical cold thyroid cancer who received the same treatment. ${ }^{6}$ It seems therefore reasonable to follow the same guidelines and standard of care used for cold thyroid cancers. Once again, however, the relatively small number of cases makes it difficult to draw adequate conclusions and larger cohorts of patients would be required to establish specific guidelines.

\section{CONCLUSION}

Our conclusion is that although it is difficult to assess the real incidence of hot thyroid carcinomas, they seem to be very rare. About 40 well-documented cases fulfilling all the necessary criteria are reported in the medical literature over the past 50 years. Most of them are follicular carcinoma. The current guidelines, which consider hot nodules to be virtually always benign, need not be changed in our opinion but clinicians should keep in mind the possibility of a malignant hot nodule and perform additional diagnostic procedures if there are any suspicious or nonconcordant findings in the preoperative assessment and workup. The surgeon should be aware of that rare possibility and use frozen section liberally if he finds any suspicious morphologic signs. If the hot nodule is diagnosed as a thyroid carcinoma, it should be managed according to the current guidelines for classical cold thyroid carcinomas.

\section{REFERENCES}

1. Paul SJ, Sisson JC. Thyrotoxicosis caused by thyroid cancer. Endocrinol Metab Clin North Am 1990;19(3):593-612.

2. Mazzaferri EL. Management of a solitary thyroid nodule. N Eng J Med 1993;328:553-59.

3. David E, Rosen IB, Bain J, James J, Kirsh JC. Management of the hot thyroid nodule. Am J Surg 1995;170(5):481-83.

4. Gabriele R, Letizia C, Borghese M, De Toma G, Celi M, Izzo L, Cavallaro A. Thyroid cancer in patients with hyperthyroidism. Horm Res 2003;60:79-83.

5. Chigot JP, Ménégaux F, Keopadabsy K, Hoang C, Aurengo A, Leenhardt L, et al. Thyroid cancer in patients with hyperthyroidism. Presse Med 2000;29(36):1969-72.

6. Als C, Gedeon P, Rösler H, Minder C, Netzer P, Laissue JA. Survival analysis of 19 patients with toxic thyroid carcinoma. J Clin Endocrinol Metab 2002;87(9):4122-27.
7. Rösler H, Wimpfheimer C, Ruchti C, Kinser J, Teuscher J. Hyperthyroidism in thyroid cancer. Retrospective study of 53 cases. Nuklearmedizin 1984;23(6):293-300.

8. Terzioğlu T, Tezelman S, Onaran Y, Tanakol R. Concurrent hyperthyroidism and thyroid carcinoma. Br J Surg 1993;80(10): 1301-02.

9. Cooper DS, Doherty GM, Haugen BR, Kloos RT, Lee SL, Mandel SJ, et al. Revised American Thyroid Association management guidelines for patients with thyroid nodules and differentiated thyroid cancer. American Thyroid Association (ATA) Guidelines Taskforce on thyroid nodules and differentiated thyroid cancer. Thyroid 2009;19(11):1167-214.

10. Schröder S, Marthaler B. Autonomy and malignancy of thyroid gland tumors. A critical analysis of the literature on the existence of hyperfunctioning follicular and papillary thyroid gland carcinomas. Pathologe 1996;17(5):349-57.

11. Lupi A, Orsolon P, Cerisara D, Deantoni-Migliorati G, VianelloDri A. Hot carcinoma of the thyroid. Case reports and comments on the literature. Minerva Endocrinol 2002;27:53-57.

12. Nishida AT, Hirano S, Asato R, Tanaka S, Kitani Y, Honda N, et al. Multifocal hyperfunctioning thyroid carcinoma without metastases. Auris Nasus Larynx 2008;35(3):432-36.

13. Damle N, Gupta S, Kumar P, Mathur S, Bal C. Papillary carcinoma masquerading as clinically toxic adenoma in very young children. J Pediatr Endocrinol Metab 2011;24(11-12): 1051-154.

14. Karanchi H, Hamilton DJ, Robbins RJ. Hürthle cell carcinoma of the thyroid presenting as thyrotoxicosis. Endocr Pract 2012; 18(1):5-9.

15. Yalla NM, Reynolds LR. Hürthle cell thyroid carcinoma presenting as a hot nodule. Endocr Pract 2011;17(3):68-72.

16. Giovanella L, Fasolini F, Suriano S, Mazzucchelli L. Hyperfunctioning solid/trabecular follicular carcinoma of the thyroid gland. J Oncol 2010;2010. pii:635984.

17. Bommireddipalli S, Goel S, Gadiraju R, Paniz-MondolFi A, DePuey EG. Follicular variant of papillary thyroid carcinoma presenting as a toxic nodule by I-123 scintigraphy. Clin Nucl Med 2010;35(10):770-75.

18. Azevedo MF, Casulari LA. Hyperfunctioning thyroid cancer: A five-year follow-up. Arq Bras Endocrinol Metabol 2010;54(1): 78-80.

19. Uludag M, Yetkin G, Citgez B, Isgor A, Basak T. Autonomously functioning thyroid nodule treated with radioactive iodine and later diagnosed as papillary thyroid cancer. Hormones (Athens) 2008;7(2):175-79.

20. Low SC, Sinha AK, Sundram FX. Detection of thyroid malignancy in a hot nodule by fluorine-18-fluorodeoxyglucose positron emission tomography. Singapore Med J 2005;46(6): 304-07.

21. Cirillo RL Jr, Pozderac RV, Caniano DA, Falko JM. Metastatic pure papillary thyroid carcinoma presenting as a toxic hot nodule. Clin Nucl Med 1998;23(6):345-49.

22. Ikekubo K, Hino M, Ito H, Otani M, Yamaguchi H, Saiki Y, et al. Thyroid carcinoma in solitary hot thyroid lesions on Tc-99m sodium pertechnetate scans. Ann Nucl Med 1989;3(1):31-36.

23. Smith M, McHenry C, Jarosz H, Lawrence AM, Paloyan E. Carcinoma of the thyroid in patients with autonomous nodules. Am Surg 1988;54(7):448-49.

24. Sandler MP, Fellmeth B, Salhany KE, Patton JA. Thyroid carcinoma masquerading as a solitary benign hyperfunctioning nodule. Clin Nucl Med 1988;13(6):410-15. 
25. Niedziela M, Breborowicz D, Trejster E, Korman E. Hot nodules in children and adolescents in western Poland from 1996 to 2000: Clinical analysis of 31 patients. J Pediatr Endocrinol Metab 2002;15(6):823-30.

26. Gharib H, Papini E, Valcavi R, Baskin HJ, Crescenzi A, Dottorini ME, et al. American Association of Clinical Endocrinologists and Associazione Medici Endocrinologi medical guidelines for clinical practice for the diagnosis and management of thyroid nodules. Endocr Pract 2006;12(1):63-102.

27. Pacini F, Castagna MG, Brilli L, Pentheroudakis G. ESMO Guidelines Working Group. Thyroid cancer: ESMO Clinical Practice Guidelines for diagnosis, treatment and follow-up. Ann Oncol 2010;21 Suppl 5:v214-19.

\section{ABOUT THE AUTHORS}

\section{Pouya Iranmanesh (Corresponding Author)}

Resident, Department of Thoracic and Endocrine Surgery Geneva University Hospitals, Geneva, Switzerland, e-mail: pouya.iranmanesh@hcuge.ch

\section{Marc Pusztaszeri}

Senior Attending, Department of Pathology, Geneva University Hospitals, Geneva, Switzerland

\section{John Robert}

Professor, Department of Thoracic and Endocrine Surgery, Geneva University Hospitals, Geneva, Switzerland

\section{Patrick Meyer}

Senior Attending, Department of Endocrinology, Geneva University Hospitals , Geneva, Switzerland

\section{Boris Schiltz}

Resident, Department of Thoracic and Endocrine Surgery, Geneva University Hospitals, Geneva, Switzerland

\section{Samira Mercedes Sadowski}

Resident, Department of Thoracic and Endocrine Surgery, Geneva University Hospitals, Geneva, Switzerland

\section{Michel Olivier Goumaz}

Private Practice, Geneva, Switzerland

\section{Frederic Triponez}

Senior Attending with Private Docent, Department of Thoracic and Endocrine Surgery, Geneva University Hospitals, Geneva, Switzerland 